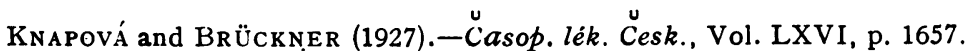

KotSU KA (1937).-Zentralbl.f.d. ges. Ophthal., Vol. XXXIX, p. 317.

PASTORE.-Soc. Oftal. Ital. 1925; Zentralbl. f. d. ges. Ophthal., Vol. XVII, p. 522.

Russo.-Rass. Ital. Oftal., Vol. VI, p. 72, 1937 ; Zentralbl. f. d. ges. Ophthal. Vol. XLI, p. 279.

SALUS (1917).-Wien. klin. Wochenschr., p. 1472.

VoGT (1929).-Klin. Monatsbl. f. Augenheilk., Vol. LXXXII, p. 433.

\title{
RETINOPATHIA CENTRALIS ANGIOSPASTICA (ANGIONEUROTICA), AND SEROSA ALLERGICA, AND THEIR RELATION TO DETACHMENT OF THE RETINA
}

\author{
BY \\ Professor ARnold Loewenstein, M.D. \\ (FROM THE TENNENT MEMORIAL INSTITUTE OF OPHTHALMOLOGY, \\ GLASGOW UNIVERSITY. PROF. A. J. BALLANTYNE)
}

CIRCUMSCRIBED disturbances of the retina, ophthalmoscopically recognisable, are found almost exclusively in the area of the macula, since a slight disturbance of function is not striking enough when a peripheral sector is concerned. A considerable number of such exudative processes in the macular area have been published as more or less rare solitary findings under different names. (Albrecht v. Graefe, Hirschberg, E. Fuchs, R. Batten, Kraupa, Asayama, Kitahara, Walsh and Sloan, Masuda, Oguchi, Guist, Reh, Hery, Junius, Stern, Suganuma, Kiewe and Reh, Cattaneo, Dollar, Abe, Bailliart, G. von Grolman, E. B. Streiff, Bangerta-Blaser, Avizonis. It is greatly to Horniker's credit (1929 and 1937) that he stressed the striking fact that the macular tissue is very easily injured by vessel disturbances. In several papers he described exactly the picture of retinitis centralis angioneurotica. Not infrequently narrowing of the capillaries of the retina, proved endoscopically, is the source of the affection. The present author himself has an experience of the astonishing figure of 72 cases, according to his last paper referring to this subject. They show a pathological form of reaction possibly of hereditary origin-an actual constitutional peculiarity. The angioneurotic constitution may have some connection with lues in the second and third generation (Kraupa), a question about which we are not yet well informed. The analogy to intermittent claudication, to migraine, to amaurosis partialis fugax and to bronchial asthma seems to be clear. Horniker measured the capillary pressure endoscopically with the ophthalmo-dynamometer. The visible rotating movement within the retinal blood vessels becomes slower under a certain pressure. 
Kitahara (1936) on the other side describes a large series of cases of chorio-retinitis centralis in Japan. These he believes to be tuberculous, as many of the cases showed a picture like solitary tubercle. Horniker refutes any resemblance to a central solitary tubercle, and I agree with him. A positive tuberculin-prickreaction alone does not entitle us to call an eye infection a tuberculous one. On the other hand I should like to emphasise at the beginning of these arguments that we must not always think of a caseation process when we speak of a tuberculous reaction of the tissue. It is much commoner for the tuberculous infection to occur histologically as an uncharacteristic, chronic, inflammation with or without production of an exudate-very often, too, without epithelioid or giant cells. Previously Allen K. Krause (1927) stressed the fact that we should not limit the use of the term " tubercular" to nodular formations, or we would overlook some of the commonest and most important anatomical manifestations of tuberculosis. Diffuse inflammation and suppuration may be caused by tubercle bacilli, these having little or nothing to do with the nodular structure. The central process in the retina might be tuberculous in its nature, even without a caseating tuberculous reaction, and different in its clinical picture. Streiff (1939) tries to separate chorio retinitis centralis serosa from Koniker's angiospastic retinopathy entirely.

Sanford Gifford and Marquart (1939) have communicated a series of eight cases lately, and emphasise the capillaro-spastic origin of the retinal changes. The affection is a transient one, and almost always disappears, with complete restoration of vision. As the changes in the ophthalmoscopic picture are very slight, the production of oedema cannot be anything else than the result of angiospasm. The authors found that their patients usually suffered from angiospastic changes in different parts of the body, that vaso-dilating drugs acted favourably, and neither tuberculosis, lues nor any blood disease was to be found. They summarised not only their own cases, but also all previous cases described as angiospastic, and used the non-committal term " retinopathy" in preference to " retinitis."

There seems to be a difference of opinion, not easily overcome. The one group (Kitasato, Riehm, Guist, etc.) call the central retinal process a specific one (in the majority tuberculous), the exudate being infective and inflammatory. Horniker, Gifford and others take the vaso-spastic character of the retinal change for granted, based on a constitutional state, and do not accept the idea of infection. It seems to be very difficult to bridge the gap between these two very different opinions.

I regret that my cases were seen some time ago, and that I have no contact with them now, so I cannot investigate the capillary 
system as I had hoped to do, but there are a number of questions which still remain to be discussed, and new conditions and relations appear in connection with the description of new cases belonging to the very interesting group of transient macular oedema.

CASE 1.-K.R., aged 41 years, neurasthenic man; smokes five cigars daily; no alcohol; headaches very often, but no actual migraine; no tuberculosis, no lues, no anomalies of the vessels or ispastic changes; nasal sinuses normal; teeth (X-ray plate) normal ; complains of seeing colours, and has micropsia and metamorphopsia. All objects appear at first bright red, then yellow, green and finally violet. At the point of fixation he sees a dark spot. Left eye normal-vision $6 / 5$.

Right Eye. No exophthalmos; normal eye movements; no pain on retropulsion ; anterior part of the eye normal ; media clear ; disc normal; no papilloedema. In the macular region opaque and slightly elevated area without sharp limits. Relative central scotoma for all colours with $3 \mathrm{~mm}$. objects. All colours are opaque, vague and undefined. The angle of the central scotoma is $6-8^{\circ}$. Vision 6/18 without correction (a year previously when controlled by me 6/5). Treatment: Sweating cure, old tuberculin intracutaneously (always a slight skin reaction), purging, cocaineadrenalin treatment of the mucosa of the nose, ultra-violet light to the sclera; micropsia and metamorphopsia disappeared within six days. The macular oedema disappeared in eight to ten days, leaving deep-lying greyish-yellow spots round the fovea. These did not vanish during the succeeding six years. The colour phenomena faded in one week. It was interesting to note that the order of disappearance of the colours was quite the reverse of their appearance. The red faded last. Four weeks after the beginning of the affection all symptoms had passed away. A relapse after two years in the same eye followed the same course, even the colours coming and going in the same succession as in the first inflammation. But the vision was not so poor as at the first attack (6/12). The greyish spots were to be observed during the whole three weeks. No relapse. Patient examined once a year.

CASE 2.-V.F., aged 37 years; tall, delicate person; old dry pleurisy with incidental increase of temperature. Capillaroscopy -normal findings; no lues; no migraine; no allergic manifestation; blood pressure normal; non-alcoholic; non-smoker.

Left Eye. -3.5 D.Sph. $=6 / 5$.

Right Eye. For the past six to eight days the right eye has been seeing everything smaller and distorted. All objects are coloured dirty greenish. To-day the visual acuity in the right eye $=6 / 18$ with correction.

Right palpebral fissure larger than left (22:17 mm.). Movements 
up of the right eye are limited; no double vision ; retropulsion and extreme movements not painful; anterior part of the eye normal; media clear; disc normal.

In the macular region, occupying the whole area, there is an egg-shaped prominence sharply defined and with an unbroken linear reflex (Fig. 1). The whole prominence is of perfect smoothness, reflecting like glass, without any superficial dots. The extremity only, proximal to the disc, is a little greyish and hazy. The measurements of the prominence are: Horizontal diameter

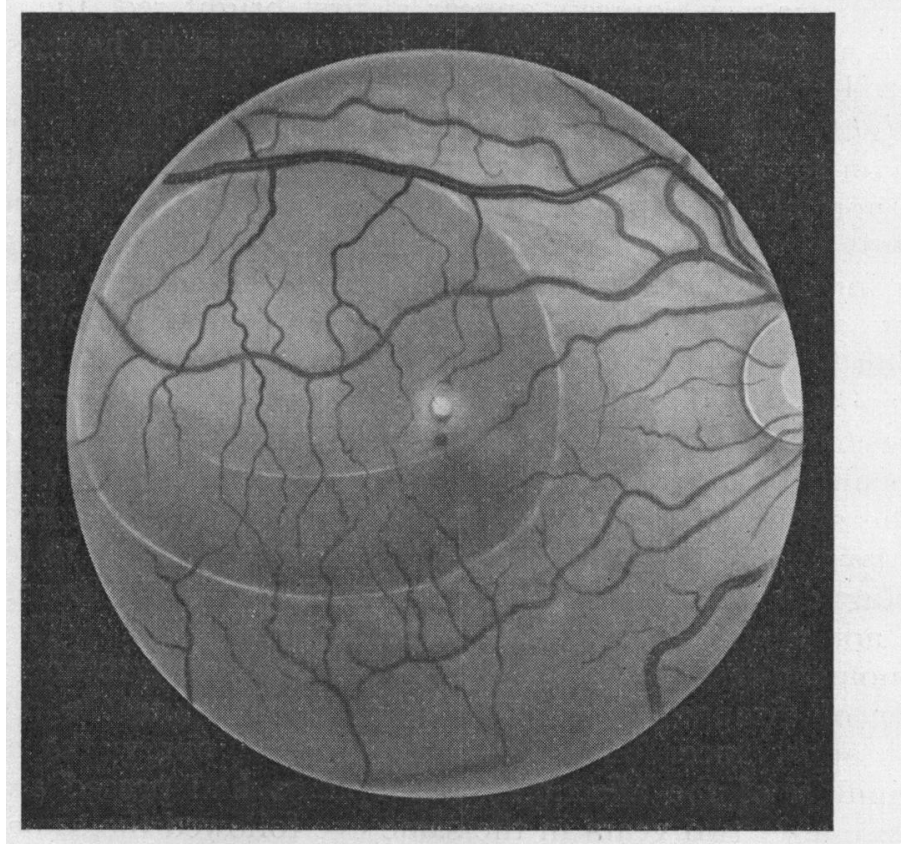

Fig. 1.

Central serous allergic retinopathy.

$4 \frac{1}{2}$ d.d., vertical diameter $3 \frac{1}{2}$ d.d. By direct ophthalmoscopy the elevation is 3 dioptres. No pigmentation, no trembling during movements of the eye; no hole in the retina. The whole fovea is brownish-yellow in the light of Vogt's direct current arc lamp. The slope of the lower-outer margin is steeper that than of the upperinner one. Besides the marginal reflex line there is another reflex arc a little down from the vertex of the prominence, running parallel to the lower margin reflex. The periphery of the fundus is normal. There is no actual central scotoma, but in a central area approximately $10^{\circ}$ from the fixation point blue becomes green, white yellowish-green. All other colours are named correctly, but 
called dirty. Outer limits of the field of vision normal. Old tuberculin $0.1 \mathrm{mg}$. intracutaneously, extensive skin reaction, no fever, no local reaction in the retina visible with Gullstrand's binocular ophthalmoscope. Transillumination with Hertzell's diaphanoscope : no shadow.

I could not exclude the possibility of a commencing tumour, but believed it rather to be a local exudate, and treated it with intracutaneous tuberculin, diathermy and diet. For three months

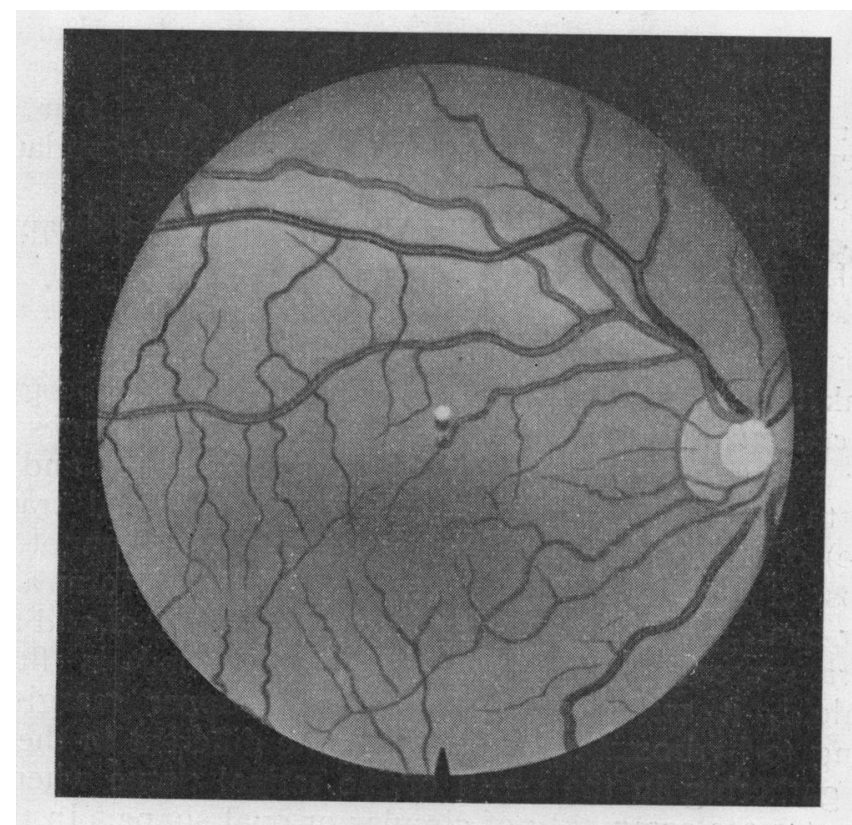

Fig. 2.

Central serous retinopathy-healed.

the prominence became flatter, the micropsia vanished and also the poor vision, as well as the exophthalmos and limitation of eye movement (Fig. 2). After six months all the symptoms had disappeared. Some tiny, deep-lying yellowish-grey pigment spots, similar to snuff-tobacco, in the macular region, remained unchanged (not showing in the photo-Fig. 2). No relapse observed during observation of $1 \frac{1}{2}$ years.

CASE 3.-H. (Seen with Dr. I. C. Michaelson). His remarks are: Girl, aged 22 years. X-ray negative. Internal examination normal, slight anaemia. 1936/37: Both eyes inflamed (iridocyclitis).

Left Eye. (June, 1938.) Many corneal precipitates. In the 
lower part of the cornea two large ones. Pinkish grey nodules in the ciliary part of the iris.

Right Eye. Posterior synechiae. Lens normal.

Vision : 6/12 right eye; 6/12 left eye, both without correction.

Tuberculin treatment; dionin; U.V. light baths.

Precipitates disappeared within half a year.

May, 1939, eyes white. Vision of the right eye diminished to "fingers" at 4 metres; no micropsia. External appearance normal. Right macular region surrounded by an uninterrupted linear reflex. Slight but definite oval prominence-smooth surface; sharp limit. Treatment discontinued. Patient on holiday.

3.VII. Getting better. Vision $=8 / 24$ after four weeks. Prominence still recognisable. In the centre of the exudate a red spot like a haemorrhage. Periphery normal.

7.VII. 8/18. Exudate within the macular area disappeared.

3.VIII. Vision $=6 / 9$. No macular change.

I think that these three cases certainly belong to the group of serous central retinopathy. In all three the changes in the macular region were absolutely evident, in Cases 2 and 3 very similar to each other, with a sub- or intra-retinal transudate (exudate) of oval or circular regular shape. We cannot explain why most of these collections of intra-retinal fluid form a regular circle or oval. That must follow from some physical and anatomical arrangement. As long as effused blood is fluid and sub-hyaloid, it settles with a horizontal upper marginal line according to hydrostatic laws. It is quite different in the case of a fluid gathering in the depth of the retinal tissue where blood extravasates are commonly of circular or oval shape. In the cases mentioned here the scaffolding of the macular region influences the form of these deposits.

It is very difficult to prove an actual spasm of the small macular vessels-Scheerer's endoscopic methods may possibly succeed, but I have no experience of them.

The ophthalmoscopic observation of arteriolar spasm has been recorded several times in the last few years. The authors have usually dealt with young women and with elderly arterio-sclerotic persons. In younger women it occurs suddenly, and constriction of the whole retinal tree or of some branches is observed. The sight is restored after a few minutes. Many of the patients suffer from migraine (H. Friedenwald, 1926). However, no clinical symptoms like ours are known in those cases. The ophthalmoscopic picture of isolated arteriolar branch thrombosis (J. Friedenwald) is a different one. 
Further we have to make it clear that our cases did not show signs of Buerger-Winiwarter's endangiitis obliterans or of morbus Raynaud or of quinine intoxication.

The significance of the transient narrowing of the small vessels (capillary spasm) in the ophthalmic investigation of cerebral disease is of growing importance. Migraine, for example, is already mostly recognised as caused by a spastic narrowing of certain brain-vessels. The closely related amaurosis partialis fugax with consecutive migraine is often described as the precursor of a so-called embolism-more probably a spastic contraction-of the central retinal artery (Roemer, Löhlein, etc.).

Such a spastic contraction might be of a reflex nature from a focus in the teeth (granuloma), as was proved in a striking case by Redslob (1931). There is no doubt that an arterial constriction in the retina can persist for a prolonged period as this author has succeeded in provoking a spasm of the retinal arteries of some months' duration by one adrenalin injection.

It is very difficult to decide whether the above processes are all based on the spastic narrowing of the vessels only-or if the exudation associated with it influences the clinical picture. No one has proved so far the connection between capillaro-spasm and exudation. The lack of anatomical findings hinders a definite decision.

After a great number of debates in the literature of the whole world, migraine is recognised as an allergic disease, with the allergen till now unknown, or certainly not recognised. Allergic oedema is emphasised by all observers as the most striking of all allergic processes in the eye tissues, the oedema being due to

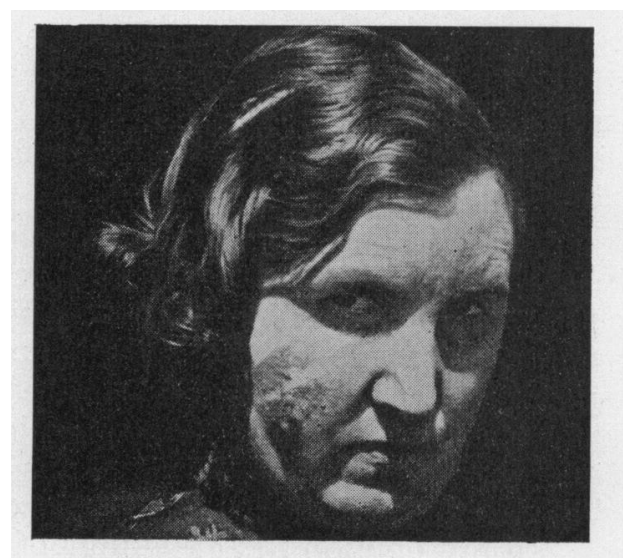

FIG. 3.

Allergic bullous dermatitis after applying a strip of plaster at the cheek. 
reduction of the colloid osmotic pressure in the vessel-system. We are surprised by the great reaction of the skin after painting the eyelids of an iodine-sensitive person-a reaction which looks like an erysipelas of the most severe kind. Figure 3 shows a 42-year old lady with such a swelling, with large serous vesicles in the skin of the face after the application of a strip of plaster. I have seen a giant oedema of the lids and the whole face half an hour after the patient had enjoyed eating crayfish soup. Intermittent, angio-neurotic paroxysmal oedema of the cornea is described by Foster-Kennedy. It comes from an alimentary source. Schieck, Loewenstein, and others, described the exudative state of iridocyclitis as an anaphylactic one in conformity with the results of many animal experiments. Meniere's vertigo, very often combined with Quincke's oedema and transient iritis is explained by allergic spasm of the vessels. Haziness of the centre of the field of vision has been described by Plumer. There was an oedema in the macular region, with an internal allergy against a special kind of food (chicken meat and walnuts). I saw a so-called embolism of the central retinal artery (better spasm), with a primary retinal oedema in a 47-year old man who had had all his life an intensive allergy against milk.

Klinge's (1930) well-known experiments were dedicated to the clearing up of the aetiology of rheumatism of the joints and muscles. He injected horse-serum subcutaneously into rabbits and re-injected some of the same serum into the joint after some time. He produced very great changes in the joint, and even very characteristic nodular foci in several spots of the body (myocardium and cardiac valves, tendons, muscles). Swelling, waxy degeneration and necrosis play a great part in producing the anatomical changes. Especially in the endothelium of the small vessels the enlargement of the cells leads to narrowing of the lumen and finally to an actual occlusion of the vessel followed by disturbance of the nutrition of the tissue. Oedema of the mesenchyma is nearly always observed as the first consequence of the vessel blockage by the allergic noxa.

F. Maxwell Lyons (1939) in the eleventh annual report of the Memorial Ophthalmic Laboratory of Giza describes a most remarkable fact about spring catarrh. The conjunctiva dries out in these cases under observation with the slit-lamp, and tiny droplets like dew appear all over the exposed surface of the conjunctiva of the lid. They increase in size until they coalesce and form a thin but tenacious film. The membrane contains a true exudation of fibrin and blood cells which must come from the sub-conjunctival capillaries. In my opinion these findings of Maxwell Lyons leave absolutely no reason to doubt the allergic nature of spring catarrh, sometimes argued against. Indeed the exudation and the 
localised chemosis at the limbal region, described as the earliest sign of bulbar involvement by this author, go to prove the allergic character of the affection. Hans Horst Meyer and Chiari published twenty years ago the surprising fact that doses of calcium are able to stop the serous exudation of the nasal and conjunctival mucosa. So it is easily understood that calcium can heal the pathological leakage in spring catarrh by tightening the vessels, and thus improve the clinical manifestations-as Maxwell Lyons has shown in his patients.

All the facts quoted here support the opinion that an allergic vessel reaction is released in cases of allergy, the cause of which often remains unknown, which is followed by a striking oedema.

Very often it is a hereditary structure of the cells which determines the quality of reaction with one or several antigens. That is if the antibody is in the cell plasma pre-existing, and antigen (allergen) brought into association with this antibody release a new substance of histamin character, and this works in an angiospastic manner. The mucosa of the intestine, the tissues of the brain, the conjunctiva and the mucosa of the nose of these patients contain these antibodies. But these antibodies arise too on exposure to certain kinds of infection by organisms of low virulence diffused into the blood from a distant focus. More often the tubercle-bacillus forms a chronic focus with a regular production of allergy. A new batch of the micro-organism from the spreading focus meets the allergic tissue, the combined allergen-antibody frees the toxic substance, and there is a spastic reaction of the vessels which leads to reduced nourishment and oedema. " $A l l$ inflammatory features of tuberculosis are allergic" (A. E. Krause).

Not infrequently we observe in a fresh tuberculous scleritis nothing but a circumscribed chemotic swelling of the conjunctiva. This disappears in the next few days, and then we recognise the infiltration of the sclera. If the scleral infiltration is situated very deeply, exudate moves not only towards the conjunctiva, but also towards the retina. Where it collects-sub-choroidally or subretinally-depends on circumstances not known to us exactly (inflammatory adhesions, concentration of albumen, etc.).

I take Case 2 to be a posterior scleritis, with allergic reaction. The inflammatory reaction towards the orbital side causes swelling of the retrobulbar tissues and hence the exophthalmos and the limitation of eye movements, the serous exudation under or in the retina, the prominence in the macular region. There was no exophthalmos in Cases 1 and 3, where the spastic allergic inflammation of the choroid produced an exudate towards the retina only. No actual caseous tubercle developed. The tissue resistance was sufficient to overcome the bacilli present and to render them harmless. It is probable that the previous tuberculin treatment 
in Case 3 shared in this favourable biological reaction. The production of exudate in this case had temporarily a worse effect than in Case 1 or 2-the transient reduction of the visual acuity going further.

Case 3 is so far clearer, as here the specific inflammation of the iris with its typical tuberculous nodules does not leave any doubt about the character of the disease.

Czillag (1937) described a case of scleritis with oedema of the conjunctiva in a woman with multiple sclerosis. At the site of the scleritis a nearly total detachment of the retina arose. With X-ray and Ektebin treatment, the scleritis healed simultaneously with the detachment. Visual acuity rose from $1 / 60$ to $5 / 5$. In this case exudate spread in both directions as in our Case 2, producing chemosis of the conjunctiva and detachment of the retina. The retina returned to its old place when the production of exudate stopped, as no cause for the progression of the detachment was present.

Steffen Lund (1938) published a similar case. It was in a woman of 50 years treated for tuberculosis at the Finsen Institute and at the Eye Clinic, with several relapses of scleritis in both eyes, sometimes combined with severe oedema of the lids and chemosis. While suffering from right-sided scleritis, the patient had a relapse in November, 1935, with oedematous swelling of the bulbar conjunctiva, an extensive detachment of the retina in the same eye, both that and the abscess of the sclera which was developing being on the nasal side. The abscess disappeared after treatment for three weeks, the retina became more and more adherent, and finally. healed, with isolated radial pigmentations and a visual acuity of $6 / 6$. There seems to be no doubt that the scleritis had given rise to the detachment of the retina, the simultaneous occurrence, the same position, the parallel running healing, not allowing any other explanation. Rumbauer's luetic scleritis (1938) with detachment may be explained on the same lines, but not with the same exactness as the retinal detachment and the scleritis did not run on parallel lines.

Other cases belonging to this interesting group have been published by Purtscher, Kamocki, Pichler. I saw a similar, but progressive case.

F.K., aged 58 years. Fair-haired, easily excited, with skin erythema very often over face and breast. Myopia $6 \mathrm{D}$.

Vision : Right eye $=6 / 8$; left eye $=6 / 12$.

Fundus : Slight myopic changes.

Left Eye. Conjunctiva of the outer-lower quadrant detached in the shape of a prominent chemotic vesicle, which persisted two months. Excision. Three months after the excision, which healed 
easily, patient complained of worse vision, with a curtain from the right side. Almost complete retinal detachment was present, the peripheral part of the inner-upper quadrant only being not detached. Horse-shoe hole very small ( $\frac{1}{4}$ P.D.) at 4 o'clockextreme periphery.

Vision. Fingers at $1 \frac{1}{2}$ metres eccentrically. Diathermic occlusion of the hole, with ball and perforating needle. Six weeks afterwards vision $=6 / 18$, right eye $=6 / 8$.

Field of vision normal. Retina in position. Histologically the excised vesicle contained a loose fluid-impregnated connective tissue, without specific cells.

The hole in the detached retina corresponded with the site of the sub-conjunctival episcleral exudate. I believe that we may explain this case by assuming an exudative process in the sclera producing a fluid stream against the conjunctiva as well as against the retina.

As a rule posterior scleritis is not detected, since clinical symptoms are often not present. An anatomical examination has only been made once (by Emanuel, 1902), so far as I am aware. He found a circumscribed tuberculous infiltration of the sclera, with caseation and giant cells, in the eye of a ten year old boy, at the posterior pole of the eye. The choroid was pushed forward at the site of inflammation, and an exudate was detected at this spot between the retina and the choroid. The rest of the retina was adherent round about with extensive scars.

Wagenmann described a case of tuberculous uveitis in a sixteen year old girl with a homogeneous exudate over the part of the choroid not so much changed. A detachment of the retina had developed.

According to our clinical and experimental experience the allergic-inflammatory process reacts by producing an exudate in its beginning only. That is understood from the case of Ginsberg (1910), where three foci of tuberculous uveitis clinically and histologically were found. In the youngest only an exudate was detected, at the site of the two older ones it was already re-absorbed. Detachment of the choroid following a relapsing scleritis is described by Fleischer, and others corresponding to the position of the scleral inflammation. The detachment of the choroid disappeared without residue before the scleritis had gone completely.

Usually the exudate is absorbed, when the inflammatory process of the sclera heals. The detached retina returns to its position, without diminution of its function. The patient in our last case was an older myope-one with the well-known biological inferiority of the retinal periphery. The Iwanoff-Blessig cysts and minor ones are the locus minoris resistentiae, where the fatal rupture sets in. It can be readily understood that the degenerated 
myopic retina, lifted by the exudate, may be injured and perforated, while a normal one would resist, and, after re-absorption of the exudate, be re-attached. The occurrence of a peripheral hole is the reason for progression in such a case of exudative detachment of the retina.

The conditions for the occurrence of an exudative retinal detachment are given when :

1. An angiospastic reaction in the sclera or choroid causes an exudate. 2. The exudate finds its way between the choroid and the retina. 3. There are no widespread adhesions between the choroid and the retina. 4. The intra-ocular pressure is not high enough, to press the retina on to the choroid.

A progressive retinal separation occurs when there is a tearable spot in a senile or myopically degenerate retina.

Experiments with rabbits (Wessely, 1921, Weekers, 1925, Loewenstein, 1926) have proved the fact that a detachment of the retina can be produced by cauterisation of the sclera. It is very easy to evoke by a slight touch with Wessely' steam cautery. The detached retina replaces itself again in a few days in the majority of cases, but in some the detachment progresses and becomes a total one. We produce here a blister in the interior of the eye raised by burning-an exudate analogous to that which accompanies an allergic inflammation.

Redslob (1931) describes a case of detachment of the retina without a retinal defect, but with a congestion of all choroidal vessels. Circulatory disturbances with physico-chemical variations of the nourishing fluids are assumed to be the cause of the detachment. Histological findings of Mawas (1935) confirm the description of Redslob, and stress the important rôle of the pigment epithelium for the retinal function. Redslob and Nordmann (1938) publish the histological picture of experimental retinal detachment in a dog, produced by a ligature of the vortex veins according to Koster. Extremely choked choroidal vessels with oedema of the pigment epithelial cells are to be seen in the spots corresponding to the detached retina. An upset in the choroidal vessel function is able to provoke a retinal detachment with cystoid degeneration even in a normal eye. Here we ignore intentionally the role of pigment epithelium and its discharge (Koyanagi, 1937), and do not mention how far damage of the qualitative and quantitative filtering power of Bruch's glass membrane influences the rise of sub- and intra-retinal exudates. (Loewenstein, 1940.)

The importance of exudative inflammation in causing detachment of the retina has been stressed very often by many authors (Dor, Lauber, Dimmer, Meller, Schall, Loewenstein, Korarskaja and Jorkima, Arruga). All these authors think that a tuberculous or other chronic inflammation of the choroid must not be under- 
estimated in the aetiology of retinal detachment. Czillag's, Steffen Lund's and my Case 4 are illustrations of this occurrence. The course of the disorder will be different according to whether the exudate meets a normal or a degenerate retinal tissue, in other words whether it produces a hole or tear in the retina or not. The well-known and not uncommon cases of spontaneous healing of retinal detachment belong mostly to the second group. The cases with retinal defect will be progressive, even if the primary process is healed. A specific treatment in all cases suspected of a tuberculous aetiology should be recommended.

We do not know why in certain cases the exudative fluid oozes into the anterior retinal tissue and in others remains in the deepest layers or sub-retinal. That may depend on the chemical constitution of this exudate. The higher the content of albumen, of fibrin, of cells, or debris, the more difficult will be the penetration of the living retina. The condition of the retina must not be neglected.

There is no doubt that a central angio-neurotic retinopathy does occur. The majority of published cases-it is a small part of those observed, and a far smaller part of those actually occurring -must convince everybody. The lability of the small vessels plays a great rôle in its :aetiology.

There will always be the question whether spastic contraction of the retinal vessels may produce the intra- or sub-retinal oedema or exudate. I am not sure about this, and want to stress the point that the choroidal vessel system is at least of the same importance for retinal nourishment, and that far-reaching changes of the ciliary (uveal) vascular system are detected in retinitis albuminurica (Koyanagi and many other authors). The cases described here are in my opinion to be explained as a sequel of choroidal reaction in the first place, even if $I$ do not exclude the effect of spastic contraction of the retinal vessels within the area round the fovea. The retinal pictures published up till now do not seem to be very convincing, but that may be due to nothing but a technical difficulty in the reproduction of such slight changes.

In analogy with migraine we have to emphasise the tendency (usually hereditary) of the capillaries to react to a certain stimulus with spasm, causing disturbance of nutrition within the area of distribution and serous imbibition of the surrounding tissue. The nature of this. stimulus is unknown in the majority of cases. The importance of the vegetative nervous system is apparent, and its connection with the endoctrine secretion. Toxic influences are possible, e.g., quinine, alcohol, nicotine, ergotin, mercury, etc. But the significance of allergic capillary spasm is not to be doubted. The commonest infection of an eye tissue is the tuberculous one, which is closely connected with the production of an allergic state of the infected tissue. Exudation is the essence of 
this allergic response. (A. K. Krause.) Our Cases 2 and 3 belong to the group of retinopathia serosa allergica tuberculosa. The importance of spasm of the small macular vessels of previously unknown origin is stressed by Horniker, Gifford and Marquart, Bailliart, Paterakis and other authors. It is very difficult to say from the long list of published cases how many are allergic. I believe that there is a great number of them. But we cannot prove this assumption. We are much better informed about the allergic origin of the Cases 2 and 3 , especially in Case 3 , with the typical tuberculous changes in the iris tissue.

So I come to the conclusion that the deep cleavage between the opinions of Horniker and Gifford on the one hand and Kitahara and Riehm on the other, is more fictitious than it seems to be on first impression. It is just possible that we may be able in a short time to prove many of the central angio-spastic retinopathies to be allergic.

\section{Summary}

One case of a central retinal process is understood to be an angio-neurotic retinopathy of unknown, probably allergic, origin. A second case with exophthalmos and limitation of eye movements with sub- or intra-macular exudate is diagnosed as posterior scleritis with exudation both into the orbital tissues and sub-retinally. A third case shows a central fundus picture analogous to the second one in connection with a typical tuberculous iridocyclitis. A fourth shows a chemotic sub-conjunctival bleb with, later on, corresponding retinal detachment in a myopic eye. The author emphasises the fact that the allergic inflammatory reaction-tuberculous or non-tuberculous-is always characterised by a primary narrowing of the smallest vessels with an oedematous imbibition of the surrounding tissue. The allergic spasm of the retinal and choroidal vessels plays a dominant part in the development of the central retinopathy. Specific processes in the choroid and sclera with exudation cause retinal detachment. In the myopic or senile retina, the occurrence of exudate in the presence of cystic degeneration may easily lead to the production of a tear in the retina and a detachment of progressive character.

\section{REFERENCES}

Bailliart (1938).-Ann. d'Ocul., Vol. CLXXV, p. 133.

Candian (1938).-Ann. di Ottal., Vol. LXVI, p. 824.

CzIllag (1937).-Klin. Monatsbl. f. Augenheilk., Vol. XCVIII, p. 206.

EMANUEL (1902).-Klin. Monatsbl.f. Augenheilk.. Vol. XL, pp. 11, 210.

FriedenWaLd, H. (1926).-Amer. Ji. Ophthal., Vol. IX, p. 831.

GIFFORD, SANFORD and MARQUART (1939).-Arch. of Ophthal., Vol. XXI, p. 211.

GinsBerg (1910).-Arch.f. Ophthal., Vol. LXXIII, p. 538.

HORNIKER (1929).-Arch.f. Ophthal., Vol. CXXIII, p. 286. 
Horniker (1937).--Klin. Monatsbl. f. Augenheilk., Vol. XCVIII, p. 478.

KITAHARA (1936).-Klin. Monatsbl. f. Augenheilk., Vol. XCVII, p. 345.

KLINGE (1930).-Virchow's Arch., Vol. CCLXXVIII, p. 438 ; Vol. CCLXXIX, p. 1, etc.

KraUSE, A. K. (1927).-The Evolution of the Tubercle. New York.

LOEWENSTEIN (1926).-Arch. f. Ophthal., Vol. CXVII, p. 130.

(1926).-Tuberkulose des Auges, Text-book: Urban and Schwarzenberg, Vienna.

(1940).-Amer. Jl. Ophthal., November and December.

LUnd, STEFFEn (1938).-Acta Ophthal., Vol. XVI, p. 414.

MaWAS (1935).-Bull. Soc. Ophtal. Franç., Vol. XLVIII, p. 379.

REDSLOB (1939).-Ophthalmica, Vol. XCVII, p. 133.

- (1931).-Bull. Soc. Ophtal., Paris, Vol. XLIV, p. 211.

REDSLOB and NORDMAN N (1938). -Bull. Soc. Ophtul. Franc., Vol. LI, p. 533.

Streiff, E. B. (1939).-Klin. Monatsbl. $f$. Augenheilk., Vol. CIII, p. 524.

RumbaUer (1938). -Klin. Monatsbl.f. Augenheilk., Vol. CI, p. 866.

WESSELy (1921).-Münch. Med. Wochenschr., p. 1670.

WEEKERS (1925). -Arch. d'Opht., Vol XLVII, p. 321.

\section{A CASE OF BLUE SCLEROTICS}

BY

\section{J. P. SPENCER WALKeR}

HOVE

THIS case of blue sclerotics may be of interest to your readers. The association of deafness and liability to fracture of bones is well known, but there is some doubt as to whether the sclera is thin and so the choroid shows through, or is of normal thickness but transparent.

There was a history of deafness of the left ear of long standing, and of recent fracture of the femur on stepping off an omnibus. As far as she knows, none of her relatives is deaf, has blue sclerotics, or has sustained fractures. The patient was brought to me by her doctor, as she had almost lost the vision of the left eye. On examination the blue sclerotics in both eyes were very noticeable, the vision of the right eye was $6 / 6$, and of the left perception of light only. The tension of the right eye was normal, but that of the left was raised considerably. The field of vision of the right eye was normal. The patient is aged 46 years.

As the tension did not lessen with the use of miotics, I decided to trephine the left eye. Though I expected the sclera might be thin, I was surprised to find how very thin it proved to be. One complete turn of the Elliot's trephine was sufficient to cut through.

My object in reporting this case is not to discuss the treatment of the glaucoma, but to draw attention to the thinness of the sclera, and to the absence of stretching of the sclera with such an increased tension in an eye with so thin an outer coat. . 